\title{
Restrained Search Predictive Control of Dual Three-phase Induction Motor Drives
}

\author{
M.J. Durán ${ }^{1}$, M.R. Arahal' ${ }^{2}$, F.J. Barrero' ${ }^{2}$, S.L. Toral ${ }^{2}$ and R. Gregor ${ }^{2}$ \\ ${ }^{1}$ Department of Electrical Engineering \\ University of Málaga \\ Plaza del Ejido S/N, 29013 Málaga (Spain) \\ Phone/Fax number:+0034 952 131091, e-mail: mjduran@uma.es \\ ${ }^{2}$ Department of Electronic and Automatic Engineering \\ University of Seville \\ Camino de los descubrimientos S/N, 41092, Sevilla (Spain)
}

Phone/Fax number:+0034 954 481281, email: arahal@esi.us.es, fbarrero@esi.us.es, toral@esi.us.es, rgregor@esi.us.es

\begin{abstract}
The interest in multiphase drives has re-emerged in the last decade, being the dual three-phase induction motor drive one of the most popular options. Predictive control techniques, already implemented in three-phase drives, have been recently adapted to the multiphase case. Schemes proposed so far have restricted the available number of voltage source inverter (VSI) switching vectors but do not impose any constraint on the allowable commutations of these vectors. This paper proposes not to select a subgroup of possible VSI switching vectors, but to constrain the commutations involved in the next sampling period. This procedure allows decreasing the switching period and improving the predictive control performance. The viability and effectiveness of the proposal is verified by simulation.
\end{abstract}

\section{Key words}

Multiphase drives, predictive control, PWM.

\section{Introduction}

Although the analysis and application of multiphase machines goes back to the late 1920's [1], the development and research in this area has been scarce until the beginning of the 21st century. The interest in multiphase drives has re-emerged in the last decade showing the advantages provided by the additional phases [2]. High power applications take advantage of the power splitting while high security applications benefit from the robustness provided by the redundancy of multiphase machines [3]. A niche of applications including electrical and hybrid vehicles [4]-[5], ship propulsion [6]-[7] or wind power systems [8] show a good prospect for the industrial use of multiphase drives. One of the most promising options is the use of dual three-phase induction machine with two sets of threephase windings spatially shifted by 30 electrical degrees with isolated neutral points (also called asymmetrical dual three-phase AC machine) [1]. Different control techniques, already developed and implemented in threephase machines, have been extended to the multiphase case. The most frequent control structure for $\mathrm{AC}$ drives is a cascaded scheme with an inner loop for current control and an outer loop for flux and speed control. Controllers are usually of PI type while current control is achieved by means of PWM schemes. The well-know field oriented control (FOC) and direct torque control (DTC) techniques have been successfully applied to asymmetrical six-phase machines [9]-[10], dealing with problems associated with machine and converter asymmetries. Similarly, the predicted control schemes have been recently extended to the current control of asymmetrical dual three-phase drives [11]-[12]. Predictive schemes avoid the use of PI controllers and PWM schemes which are difficult to design in multiphase drives [13]. Predictive control theory was developed by the end of the 1970s and possesses interesting features such as fast torque response and high flexibility control design [14]-[15]. Its viability has been recently proved for the current control of neutral-point-clamped converters for wind power applications [16], multilevel converters with balance dc link [17], and three-phase converters with enhanced efficiency [18]. The main shortcoming of predictive control for $\mathrm{AC}$ drives is the intensive calculations involved in determining the optimal set of VSI switching states to be applied in the next sampling time. Optimal solutions explore all possible switching states and select the VSI switching vector that minimizes a predefined cost function [13]. There are in general $2^{n}$ switching states, being $n$ the number of phases in the machine, which leads to $2^{6}=64$ possibilities for a six-phase machine. Because of the increased number of possibilities in multiphase drives, investigations developed so far have proposed suboptimal solutions based on the selection of a certain subgroup of vectors among the 64 possible options [11]-[12]. This work follows a different approach and does not discard a priori any of the 64 vectors. Instead, some constraints are imposed on the next switching vector to guarantee a maximum number of commutations in the VSI legs. With the proposed procedure a different subgroup of switching states is considered in each sampling time. The real time implementation is feasible because only a subset of vectors is examined at each sampling time and the maximum switching frequency can be decreased depending on the adopted constrain. The proposed method will be referred as restrained search predictive control (RSPC) further on and will be compare with standard predictive control (SPC) of [11]-[12]. It is worth noting that a modified predictive control scheme, termed machine hybrid torque control (MHTC) [19]-[20], has been recently proposed to enhance conventional predictive control techniques [11][14] by including a submodulation of the selected vector. Although the scheme of [19]-[20] is in principle compatible with the RSPC, it is out of the scope of this paper. The paper is structured so that the fundamentals about multiphase drives are described in section II. Section 
III details the standard predictive control and the proposed scheme is presented in section IV. Standard and proposed schemes are examined and discussed in section $\mathrm{V}$ and section VI includes the conclusions.

\section{Six-phase drive overview.}

The system under study consists of an asymmetrical dual three-phase AC machine supplied by a six-phase VSI and a dc link. A detailed scheme of the drive is provided in Fig. 1. The six-phase machine is a continuous system which can be described by a set of differential equations. Although it can be modelled using the double $\mathrm{d}-\mathrm{q}$ approach as an extension of the d-q approach of threephase machines, the most popular option is the use of the vector space decomposition (VSD) approach [2] because it better explains the physical phenomena in the machine. According to the VSD approach, the machine can be represented with three stator-rotor pairs of windings in orthogonal subspaces. One stator-rotor pair engages with electromechanical energy conversion $(\alpha-\beta$ subspace in what follows), while the others do not. The first statorrotor pair represents the fundamental supply component plus supply harmonic of the order $12 n \pm 1 \quad(n=1,2,3, \ldots)$. The other stator-rotor pairs represent supply harmonic of the order $6 n \pm 1(x-y$ subspace with $n=1,3,5, \ldots)$ plus the zero sequence harmonic components which disappear if isolated neutral points are assumed. The six-phase machine equations in $\alpha-\beta-\mathrm{x}-\mathrm{y}$ components can be expressed as:

$$
\begin{aligned}
& {\left[\begin{array}{c}
\mathrm{u}_{\alpha s} \\
\mathrm{u}_{\beta s} \\
0 \\
0
\end{array}\right]=\left[\begin{array}{cccc}
\mathrm{R}_{\mathrm{s}} & 0 & 0 & 0 \\
0 & \mathrm{R}_{\mathrm{s}} & 0 & 0 \\
0 & \omega_{\mathrm{r}} \cdot \mathrm{L}_{\mathrm{m}} & \mathrm{R}_{\mathrm{r}} & \omega_{\mathrm{r}} \cdot \mathrm{L}_{\mathrm{r}} \\
-\omega_{\mathrm{r}} \cdot \mathrm{L}_{\mathrm{m}} & 0 & -\omega_{\mathrm{r}} \cdot \mathrm{L}_{\mathrm{r}} & \mathrm{R}_{\mathrm{r}}
\end{array}\right] \cdot\left[\begin{array}{c}
\mathrm{i}_{\alpha s} \\
\mathrm{i}_{\beta \mathrm{s}} \\
\mathrm{i}_{\alpha \mathrm{r}} \\
\mathrm{i}_{\beta \mathrm{r}}
\end{array}\right]+} \\
& +\left[\begin{array}{cccc}
\mathrm{L}_{\mathrm{s}} & 0 & \mathrm{~L}_{\mathrm{m}} & 0 \\
0 & \mathrm{~L}_{\mathrm{s}} & 0 & \mathrm{~L}_{\mathrm{m}} \\
\mathrm{L}_{\mathrm{m}} & 0 & \mathrm{~L}_{\mathrm{r}} & 0 \\
0 & \mathrm{~L}_{\mathrm{m}} & 0 & \mathrm{~L}_{\mathrm{r}}
\end{array}\right] \cdot \mathrm{p} \cdot\left[\begin{array}{c}
\mathrm{i}_{\alpha \mathrm{s}} \\
\mathrm{i}_{\beta s} \\
\mathrm{i}_{\alpha \mathrm{r}} \\
\mathrm{i}_{\beta r}
\end{array}\right] \\
& {\left[\begin{array}{c}
\mathrm{u}_{\mathrm{xs}} \\
\mathrm{u}_{\mathrm{ys}}
\end{array}\right]=\left[\begin{array}{cc}
\mathrm{R}_{\mathrm{s}} & 0 \\
0 & \mathrm{R} \\
\mathrm{s}
\end{array}\right] \cdot\left[\begin{array}{c}
\mathrm{i}_{\mathrm{xs}} \\
\mathrm{i}_{\mathrm{ys}}
\end{array}\right]+\left[\begin{array}{cc}
\mathrm{L}_{\mathrm{ls}} & 0 \\
0 & \mathrm{~L}_{\mathrm{ls}}
\end{array}\right] \cdot \mathrm{p} \cdot\left[\begin{array}{l}
\mathrm{i}_{\mathrm{xs}} \\
\mathrm{i}_{\mathrm{ys}}
\end{array}\right]}
\end{aligned}
$$

It can be noted that $\alpha-\beta$ equations are similar to those of a three-phase machine while $\mathrm{x}-\mathrm{y}$ equations do not link the rotor side and consequently do not influence the machine dynamics but are just a source of Joule losses in the machine. The VSI has a discrete nature and has a total number of $2^{6}=64$ different switching states defined by six switching functions corresponding to the six inverter legs $\left[\mathrm{S}_{\mathrm{a}}, \mathrm{S}_{\mathrm{b}}, \mathrm{S}_{\mathrm{c}}, \mathrm{S}_{\mathrm{d}}, \mathrm{S}_{\mathrm{e}}, \mathrm{S}_{\mathrm{f}}\right]$, where $\mathrm{S}_{\mathrm{i}} \in\{0,1\}$. The different switching states and the voltage of the dc link $\left(V_{D C}\right)$ define the phase voltages which can in turn be mapped to the $\alpha-\beta-x-y$ space according to the VSD approach. Consequently, the 64 different on/off combinations of the six VSI legs lead to 64 space vectors in the $\alpha-\beta$ and $x-y$ subspaces. Fig. 2 shows the active vectors in the $\alpha-\beta$ and $\mathrm{x}-\mathrm{y}$ subspaces, where each vector switching state is identified using the switching function by two octal numbers corresponding to the binary numbers $\left[\mathrm{S}_{\mathrm{a}} \mathrm{S}_{\mathrm{b}} \mathrm{S}_{\mathrm{c}}\right]$ and $\left[\mathrm{S}_{\mathrm{d}} \mathrm{S}_{\mathrm{e}} \mathrm{S}_{\mathrm{f}}\right]$, respectively. For the sake of conciseness, the 64 VSI switching vectors will be usually referred as vectors in what follows. It must be noted that the 64 possibilities imply only 49 different vectors in the $\alpha-\beta-x-$ y space. Nevertheless, redundant vectors are considered as different vectors because they have a different impact on the switching frequency even though they generate identical torque and losses in the six-phase machine.

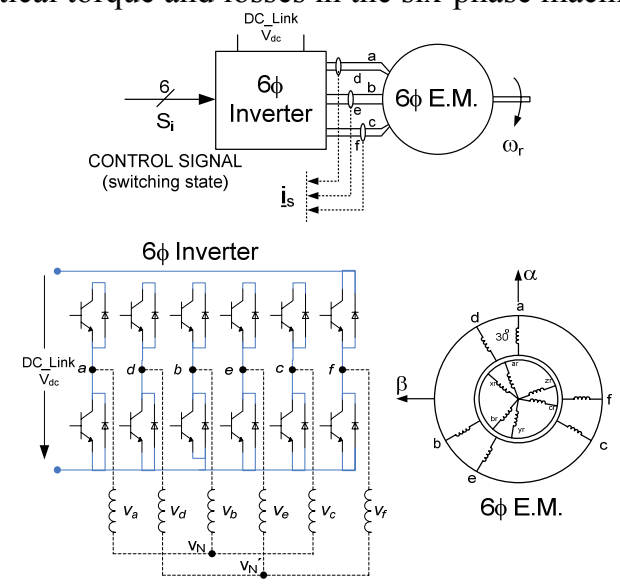

Fig. 1: A general scheme of an asymmetrical dual threephase AC drive.

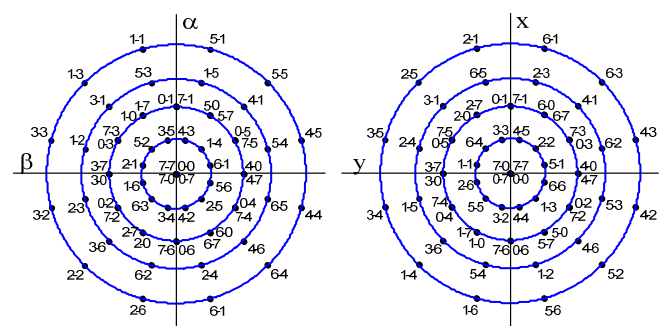

Fig. 2: Voltage vectors applied in the $\alpha-\beta$ and $x-y$ subspaces using a 6-phase VSI.

\section{Standard predictive control for six- phase drives.}

Predictive control uses a model of the drive (VSI and multiphase machine) to predict the machine operation point for each possible switching state of the VSI. The machine equations (1) can be written in state space taking stator $\alpha-\beta-x-y$ currents as state variables. The machine model must be discretised in order to be of use as a predictive model. A forward Euler method with a sampling time $T_{m}$ can be used, producing equations in the needed digital control form, with predicted variables depending just on past values and not on present values of variables:

$$
\begin{aligned}
& X(k)=\left[\begin{array}{c}
i_{\alpha s} \\
i_{\beta s} \\
i_{x s} \\
i_{y s}
\end{array}\right], U=\left[S_{a}, S_{b}, S_{c}, S_{d}, S_{e}, S_{f}\right] \\
& X(k+1)=A(k) \cdot X(k)+B(U(k))+C(k)
\end{aligned}
$$

If an exhaustive search over the 64 possible control signals is implemented, an optimal solution is achieved. Suboptimal solutions are obtained by selecting a subgroup of all 64 possible switching vectors. In [11]-[12] the performance using 49 and 13 vectors is examined. The predictive model is used for each possible switching state included in the selected subset of vectors, and the control actions are obtained solving an optimization problem aimed at minimizing a cost function. Different cost functions can be defined in order to minimize the current error [16], the commutations and the balance in the dc link 
[17] or the switching losses [18]. The cost function used for this study considers only the current error in the $\alpha-\beta$ and $\mathrm{x}-\mathrm{y}$ subspaces. For ease of notation the predicted deviations are gathered in two vectors:

$\hat{e}_{\alpha \beta}=\left[i_{\alpha}^{*}(k+1)-\hat{i}_{\alpha}(k+1 \mid k), i_{\beta}^{*}(k+1)-\hat{i}_{\beta}(k+1 \mid k)\right] \cdot \frac{1}{A_{\alpha \beta}}$

$\hat{e}_{x y}=\left[-\hat{i}_{x}(k+1 \mid k),-\hat{i}_{y}(k+1 \mid k)\right]$

being $A_{\alpha \beta}$ the amplitude of the reference signal $\left[i_{\alpha}{ }^{*}, i_{\beta}{ }^{*}\right]$. The cost function is finally defined as:

$J_{\alpha \beta x y}=\left\|\hat{e}_{\alpha \beta}\right\|+\lambda_{x y}\left\|\hat{e}_{x y}\right\|$

where $\lambda_{\mathrm{xy}}$ is a weighing factor that allows putting more emphasis on $\alpha-\beta$ or $\mathrm{x}-\mathrm{y}$ subspaces. A detailed block diagram of the conventional predictive control technique is provided in Fig. 3.

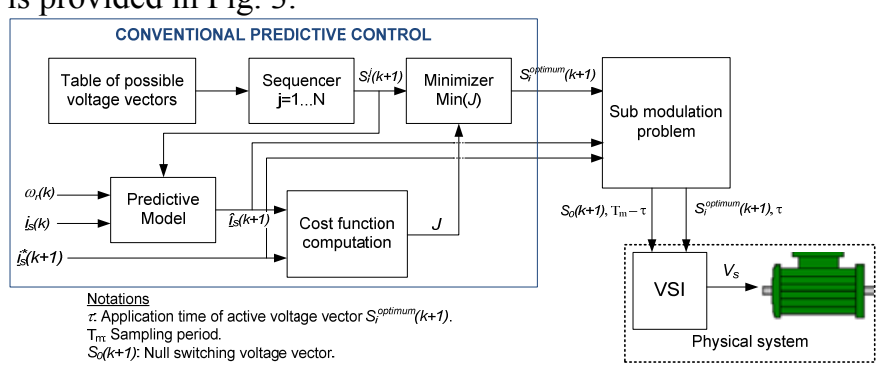

Fig. 3. General scheme of the predictive control for a sixphase drive.

\section{Restrained search predictive control for six-phase drives.}

The description of the six-phase drive and the predictive control in the preceding sections 2 and 3 are valid for the proposed restrained search predictive control (RSPC), but the voltage vector selection strategy differs from the one proposed in [12]. The predictive model remains the same but the RSPC aims at improving the selection of the subset of available vectors at each sampling time. In the standard predictive control (SPC) implemented in [11][12] the 64 total number of VSI switching vectors is reduced to 49 and 13 by eliminating redundant vectors and considering standard assumptions [11], respectively. This procedure favours the real time implementation but leads to suboptimal solutions because some vectors are discarded regardless of the operation point of the drive. Furthermore, the resulting switching frequency is variable and the number of commutations is not restricted: a new switching state can involve the commutation of only one leg or all of them. This paper proposes to select a subset of available vectors at a certain instant based on certain restrictions. The first proposed constraint aims at minimizing the number of commutations:

a) The subset of available vectors must include only the possibilities that imply only one or less commutations.

This constraint selects the vectors based on considering the preceding vector. For the sake of example, if the vector [101010] is applied at instant $k$, the subset of available vectors at instant $k+1$ would be:

$\begin{array}{ll}1^{\text {st }} \text { vector: }[101010] & 5^{\text {th }} \text { vector: }[101110] \\ 2^{\text {nd }} \text { vector: }[\underline{001010]} & 6^{\text {th }} \text { vector: }[1010 \underline{0} 0] \\ 3^{\text {rd }} \text { vector: }[1 \underline{11010]} & 7^{\text {th }} \text { vector: }[10101 \underline{0}]\end{array}$

$4^{\text {th }}$ vector: [100010]

where the underlined numbers indicate the VSI leg that has been changed. It is important to note that in spite of selecting a subset with just 7 vectors from the 64 possibilities of the optimal solution, none of the 64 vectors are discarded for all operation points. Since the 7 vectors of the subset are dependent on the previously applied vector, 7 the applicable vectors change every sampling period. The selection of these 7 vectors guarantees that at each sampling period only one leg will change its state and consequently the number of commutations is must be reduced compared to SPC [13]-[18]. Attempts to minimize the number of commutations in SPC have been carried out including a term in the cost function weighting the total number of commutations [17]. Nevertheless, the computational cost of the method increases, one has to correctly tune the commutation weighting factor and even though there is not guarantee about the number of commutations at each sampling period. The RSPC inherently minimizes commutations because the vectors are selected according to restriction a). Consequently, the RSPC achieves improved efficiency in a straightforward manner. The second constraint aims at decreasing the maximum switching frequency of each VSI leg:

b) Any of the six VSI legs must not commute in two consecutive switching periods.

This implies that one needs to know which VSI leg was changed in the last sample time to avoid changing the same VSI leg again. For the sake of example let us consider that one applied the vector [101011] at time $k-1$, and the vector [101010] at time $k$. For the next sampling time $k+1$ the sixth phase cannot be changed and only 6 vectors among the 64 comply with constraints a) and b) simultaneously:
$1^{\text {st }}$ vector: [101010]
$2^{\text {nd }}$ vector: [001010]
$4^{\text {th }}$ vector: [100010]
$5^{\text {th }}$ vector: $[101110]$
$3^{\text {rd }}$ vector: [111010]
$6^{\text {th }}$ vector: $[101000$ ]

The RSPC method combining conditions a) and b) only computes 6 vectors and for that reason will be referred as RSPC6v further on. The commutations in the SPC are not limited and consequently one leg may commute very switching period. The maximum number of commutations on SPC would be achieved if every leg changes its state in every switching period. Even in this worst scenario, the maximum switching frequency is half of the switching frequency of a standard FOC control with PWM. The reason is that PWM forces every VSI leg to commute twice in a switching period completing a cycle on/off off/on or vice versa. To the contrary, SPC commutes just once (on/off or off/on, but not both) because there is no submodulation. For that reason a PWM with a switching period $\mathrm{T}_{\mathrm{ma}}$ must be compared with a SPC with a switching period $\mathrm{T}_{\mathrm{mb}}=\mathrm{T}_{\mathrm{ma}} / 2$. Fig. 4 depict this situation showing that, in spite of using half the period for SPC, the switching frequency of the SPC is always equal or lower than that of the PWM. Note that PWM strategy in Fig. 4a involves 10 commutations while the SPC strategy involves 8 commutations. Condition b) above expressed goes one step beyond by guaranteeing that any of the six legs of the VSI will commute in two consecutive periods. This condition directly implies that the maximum switching frequency is halved. This in turn means that a SPC with a period of $\mathrm{T}_{\mathrm{mb}}$ must be compared with a $R S P C 6 v$ with a period of $\mathrm{T}_{\mathrm{mc}}=$ 
$\mathrm{T}_{\mathrm{mb}} / 2=\mathrm{T}_{\mathrm{ma}} / 4$. This condition is depicted in Fig. 4c, showing that the period is reduced down to $25 \%$ of the PWM period $\mathrm{T}_{\mathrm{ma}}$ but the technique still involves the same or less commutations than in the PWM case of Fig. 4a. Comparing cases b) and c) in Fig. 4 one can note that the maximum switching frequency is the same but in the RSPC6v technique (Fig. 4c) the commutations can occur at intermediate instants (see the commutation at $t_{\text {int }}$ in Fig.4c) providing an enhanced flexibility.
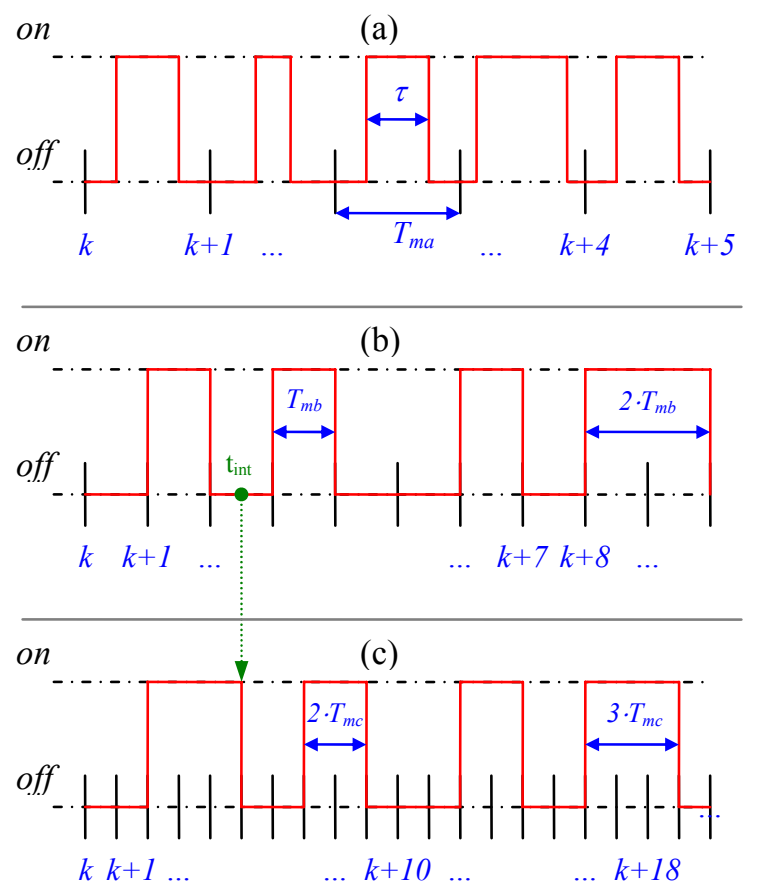

Fig. 4: Scheme of the commutations in a VSI leg when (a) PWM, (b) SPC and (c) RSPC strategies are used with switching periods of $\mathrm{T}_{\mathrm{m}}, \mathrm{T}_{\mathrm{m}} / 2$ and $\mathrm{T}_{\mathrm{m}} / 4$ respectively.

Although the RSPC can be based on different constraints, proposed restrictions a) and b) have interesting features that can be summarized as:

- Only six vectors need to be evaluated favouring the real time implementation.

- No vectors are discarded for any operation point.

- The commutations are minimized favouring the drive efficiency.

- A VSI leg can change its state at intermediate instants compared to SPC.

\section{Simulation results.}

This section examines the performance of the proposed $R S P C 6 v$ technique. It will be compared with optimal standard predictive control considering all 64 possible vectors (it will be termed as SPC64v to distinguish it from SPC techniques that use a subgroup of 49 or 13 vectors [13]-[14]). The performance of the PI+PWM method, which is the benchmark in current control techniques, will also be shown and the results will be discussed both for steady state and transient state.

\section{A. Steady state performance}

The steady state performance is firstly issued by considering a current reference with amplitude of $0.67 \mathrm{~A}$ and an angular frequency of $300 \mathrm{rad} / \mathrm{s}$ (called test 1 from now on). Four performance parameters are considered for comparison purposes:

- Mean square error of $\alpha$ current component (MSE $i_{\alpha}$ ).

- Mean square error of $x$ current component (MSE $i_{x}$ ).

- Total harmonic distortion (THD).

- Total number of commutations (TNC).

\section{1) Influence of weighting factor $\lambda_{x y}$.}

Both SCP64v and RSPC6v methods are dependent on the weighting factor $\lambda_{x y}$ and a suitable value must be achieved to obtain good $\alpha$ - $\beta$ current tracking but with low values of $x-y$ current components (note that $x-y$ components do not contribute to the overall torque generation but only generate losses). Fig. 5 shows the performance parameters against $\lambda_{x y}$ when the switching frequency of the PWM is 5 $\mathrm{kHz}$. Please note that the switching period of the different methods is characterized by the switching frequency of the PWM because the switching frequency of the SCP64v and RSPC6 is variable. In the case of Fig. 5 the switching period of the PWM is $1 / 5 \mathrm{e} 3=0.2 \mathrm{~ms}$ and the switching periods of the SCP64v and RSPC6v are $0.1 \mathrm{~ms}$ and 0.05 ms respectively. It can be noted in Fig. 5 that higher values of the weighting factor $\lambda_{x y}$ leads to higher MSE $i_{\alpha}$ and lower MSE $\mathrm{i}_{\mathrm{x}}$ for both SCP64v and RSPC $6 v$ methods as expected. The THD is reduced as $\lambda_{x y}$ increases and the TNC slightly increases. The value of $\lambda_{x y}$ is set to 0.4 in the subsequent results to obtain a good compromise between the four performance parameters. The performance at 5 $\mathrm{kHz}$ of RSPC6v is slightly better than that of the SPC64v in spite of using only 6 VSI switching vectors instead of the 64 of the optimal solution. The possibility to commute at intermediate points (as shown in Fig. 5) makes up for the reduced number of possibilities in the suboptimal solution RSPC6v. The predictive methods at $5 \mathrm{kHz}$ shows that better MSE $i_{\alpha}$ and less TNC can be achieved compared to PWM but with higher THD and MSE $\mathrm{i}_{\mathrm{x}}$.

\section{2) Influence of switching frequency $f_{s w}$.}

Since the performance of predictive methods is highly dependent on the switching frequency, Fig. 6 shows the performance parameters as a function of the switching frequency of the PWM. It can be observed that the predictive control performance (of both SCP64v and RSPC6v) highly increases as the switching period is decreased (higher switching frequency, $f_{\text {switch }}$ in Fig. 6). The RSPC6v method is better than the SCP64v in all four performance parameters under consideration. Compared to PWM method, better MSE $i_{\alpha}$ and less TNC can be achieved but with higher THD and MSE $i_{x}$. Nevertheless, the RSPC6v performance at $10 \mathrm{kHz}$ is closed to the PWM performance and the TNC is reduced in $75 \%$. This influences positively the efficiency of the VSI. 


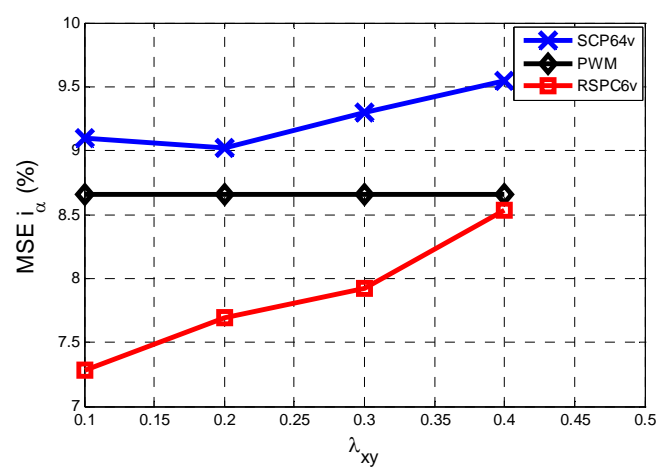

(a)

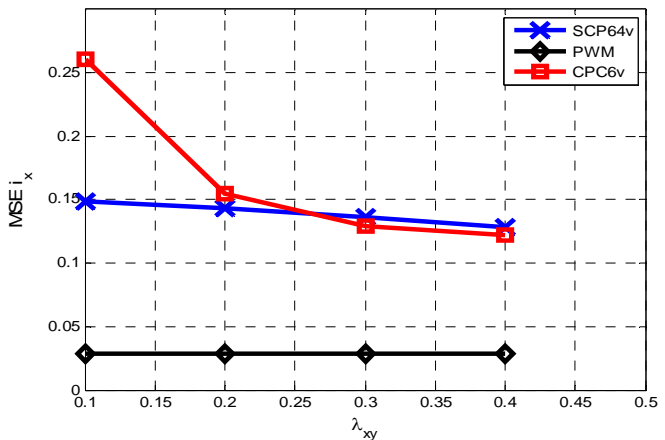

(b)

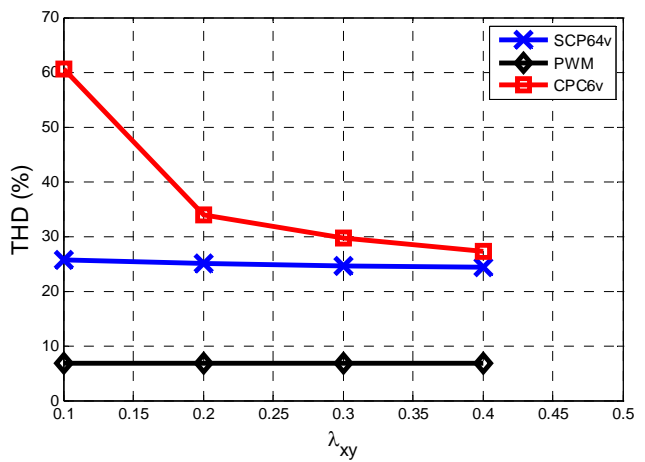

(c)

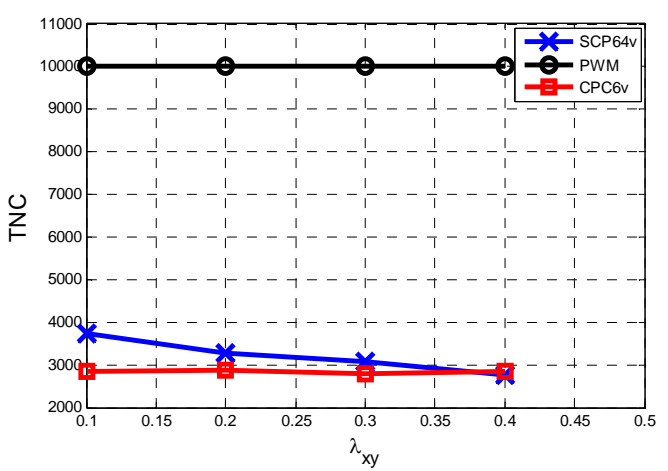

(d)

Fig. 5: MSE $i_{\alpha}$, MSE $i_{x}$, THD and TNC as a function of the weighting factor $\lambda_{x y}$ for SCP64v, RSPC6v and PWM methods (Test 1).

\section{3) Current tracking capability and voltage} waveform

The performance of the different methods has been explored so far through the calculation of four performance parameters (MSE $i_{\alpha}$, MSE $i_{x}$, THD and TNC). Figure 7 show directly the current tracking of the $\alpha$ reference current components when a switching

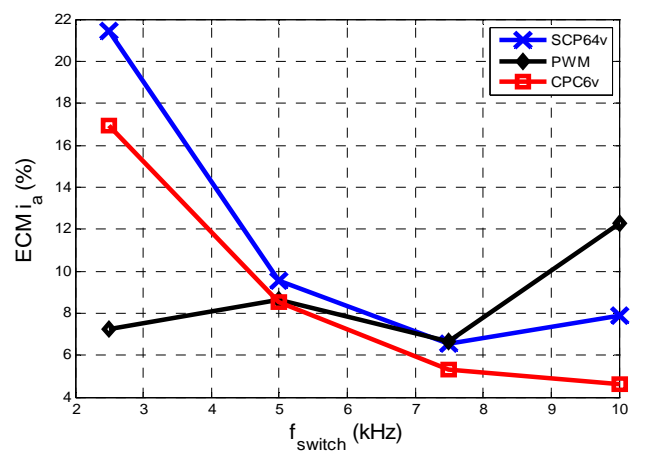

(a)

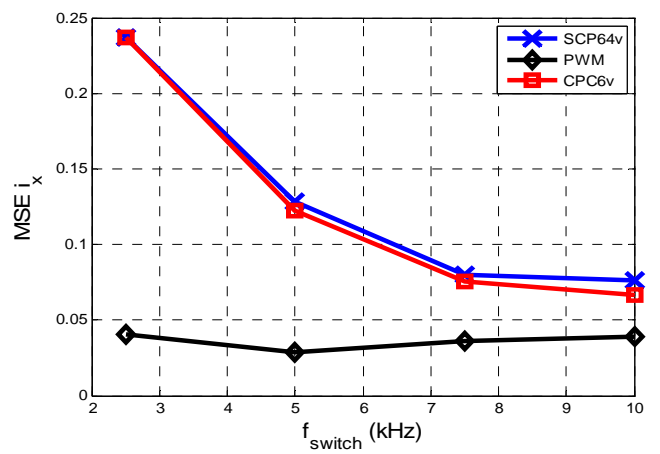

(b)

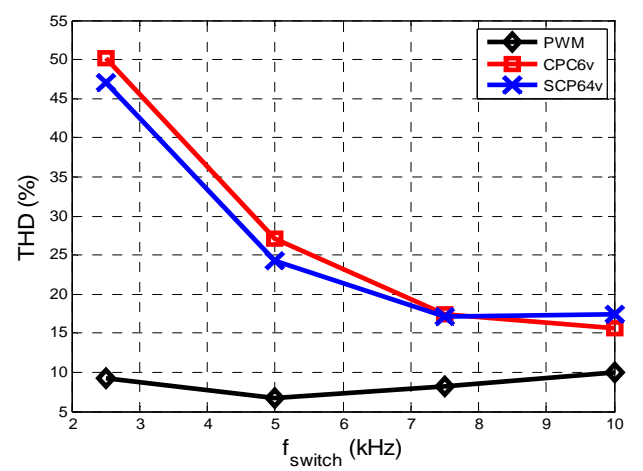

(c)

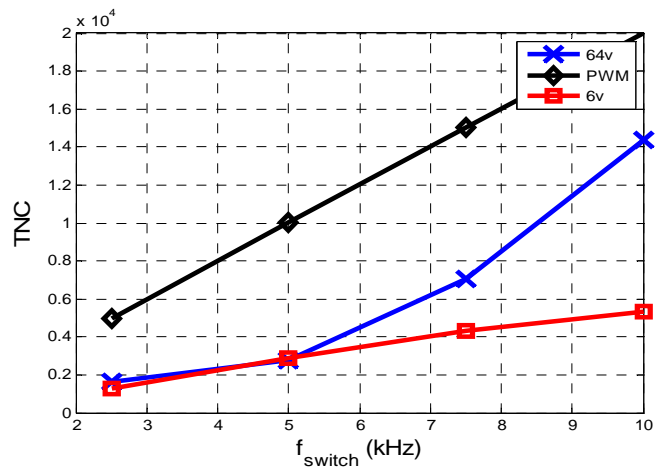

(d)

Fig. 6: MSE $i_{\alpha}$, MSE $i_{x}$, THD and TNC as a function of the weighting the PWM switching frequency for $\mathrm{SCP} 64 \mathrm{v}$, RSPC6v and PWM methods (Test 1).

frequency of $10 \mathrm{kHz}$ is used. It can be noted that the waveform of the predictive methods is very different from the PWM method. Predictive methods act quickly and follow the $\alpha$ reference correctly but with higher THD. The RSPC6 $\mathrm{v}$ proves to provide slightly enhanced performance compared to SCP64v in spite of using only 6 vectors and involving less commutations. 
4) Performance with different amplitudes and frequencies.

All results reported so far are related to test 1 , using a reference current with an amplitude $\left(\mathrm{i}_{\text {peak }}\right)$ of $0.67 \mathrm{~A}$ and an angular frequency $(\omega)$ of $300 \mathrm{rad} / \mathrm{s}$. Table 1 summarizes the results of for another two test where different amplitudes and angular frequencies for the reference current are considered:

- Test 2: $\mathrm{i}_{\text {peak }}=4.50 \mathrm{~A}$ and $\omega=300 \mathrm{rad} / \mathrm{s}$.

- Test $3: \mathrm{i}_{\text {peak }}=5.85 \mathrm{~A}$ and $\omega=30 \mathrm{rad} / \mathrm{s}$.
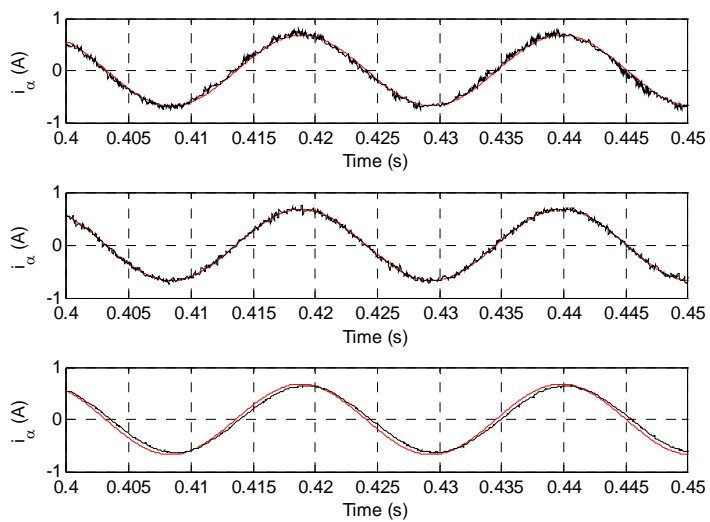

Fig. 7: Current tracking of the $\alpha$ current component for SCP64v (upper), RSPC6v (middle) and PWM (bottom) methods (Test 1).

From table 1 it can be observed that the proposed RSPC method obtains similar or even better performance than SCP and PWM methods at $10 \mathrm{kHz}$ with reduced number of commutations.

Table 1: Performance of PWM, SCP and RSPC for tests 2 - 3 .

\begin{tabular}{|c|c|c|c|c|}
\hline & \multicolumn{4}{|c|}{ Test 2} \\
\hline & MSE $\mathbf{i}_{\alpha}$ & MSE $i_{x}$ & THD & TNC \\
\hline & \multicolumn{4}{|c|}{$f_{\text {switch }}=5 \mathrm{kHz}$} \\
\hline PWM & 4.9317 & 0.0377 & 1.3763 & 10000 \\
\hline SCP64v & 7.4827 & 0.0766 & 3.2163 & 4012 \\
\hline \multirow[t]{2}{*}{ RSPC6v } & 4.2885 & 0.0854 & 6.3420 & 2610 \\
\hline & \multicolumn{4}{|c|}{$f_{\text {switch }}=10 \mathrm{kHz}$} \\
\hline PWM & 5.0289 & 0.0526 & 2.0898 & 20000 \\
\hline SCP64v & 3.5036 & 0.0544 & 2.2282 & 1.2902 \\
\hline \multirow[t]{4}{*}{ RSPC6v } & 2.1118 & 0.0509 & 3.4123 & 5587 \\
\hline & \multicolumn{4}{|c|}{ Test 3} \\
\hline & MSE $\mathbf{i}_{\alpha}$ & MSE $i_{x}$ & THD & TNC \\
\hline & \multicolumn{4}{|c|}{$f_{\text {switch }}=5 \mathrm{kHz}$} \\
\hline PWM & 3.1795 & 0.0327 & 14.3594 & 10000 \\
\hline SCP64v & 1.1617 & 0.1015 & 11.6927 & 4.6941 \\
\hline \multirow[t]{2}{*}{ RSPC6v } & 1.1996 & 0.1113 & 12.6652 & 3131 \\
\hline & \multicolumn{4}{|c|}{$f_{\text {switch }}=10 \mathrm{kHz}$} \\
\hline PWM & 3.002 & 0.0542 & 15.6421 & 20000 \\
\hline SCP64v & 0.6702 & 0.0612 & 14.1705 & 14719 \\
\hline RSPC6v & 0.6863 & 0.0601 & 11.6901 & 6159 \\
\hline
\end{tabular}

\section{Conclusions}

The main shortcoming of predictive methods is the computational cost associated with the intensive calculations. This problem, specifically relevant in multiphase drives, can be solved by imposing some constraints on the switching states under consideration at each sampling time. The proposed suboptimal solution favours the real time implementation and proves to provide similar results to the optimal solution. Compared to standard current control with PI controllers and PWM, the proposed solutions achieves similar steady state performance, better transient response and reduced number of VSI commutations.

\section{Acknowledgement}

The authors gratefully acknowledge the Spanish Government for the economical support provided within the National Research, Development and Innovation Plan, DPI2005/04438.

\section{References}

[1] P.L. Alger, E.H. Freiburghouse, D.D. Chase, "Double Windings for Turbine Alternators," AIEE Trans., vol.49, pp. 226-244, 1930.

[2] E. Levi, R. Bojoi, F. Profumo, H.A. Toliyat, S. Williamson, "Multiphase Induction Motor Drives-A Technology Status Review," Elec. Power App., IET, vol. 1, no. 4, pp. 489-516, 2007.

[3] J.R.Fu, T.A.Lipo, "Disturbance free operation of a multiphase current regulated motor drive with an opened phase," IEEE Trans. on Industry Applications, vol. 30, no. 5, 1994, pp. 1267-1274.

[4] Benatmane, M., McCoy T., Dalton, T., Cooper, T.L., 'Electric power generation and propulsion motor development for US Navy surface ships', in Proc. All Electric Ship: Developing Benefits for Maritime Applications Conf., London, U.K., 1998, pp. 89-94.

[5] Parsa, L., Toliyat, H.A., 'Fault-tolerant interior-permanent-magnet machines for hybrid electric vehicle applications', IEEE Trans. on Vehicular Technology, vol. 56, no. 4, 2007, pp. 1546-1552.

[6] Norton, P.T. and Thompson, P.E., 'The naval electric ship of today and tomorrow', in Proc. 3rd All Electric Ship Symp., Paris, France, 2000, p. 80-86.

[7] Parsa, L., Toliyat, H.A., 'Five-Phase Permanent Magnet Motor Drives for Ship Propulsion applications' in Proc. IEEE Electric Ship Tech. Symposium, Philadelphia, US, 2005 pp. 371-378.

[8] Vizireanu, D., Brisset, S., Kestelyn, X., Borchet, P., Milet, Y., Laloy, D., 'Investigation on multi-star structures for large power direct-drive wind generator', Electr. Power Comp. Syst., vol. 35, no. 2, 2007, pp. 135-152.

[9] R. Bojoi, E. Levi, F. Farina, A. Tenconi, F. Profumo, "Dual threephase induction motor drive with digital current control in the stationary reference frame," IEE Proc. Electr. Power Appl., vol. 153 , no. 1, pp. 129-139, 2006.

[10] R. Bojoi, F. Farina, G. Griva, F. Profumo, A. Tenconi, "Direct Torque Control for Dual Three-Phase Induction Motor Drives," IEEE Trans. Ind. Appl., vol. 41, no. 6, pp. 1627-1636, 2005.

[11] F. Barrero, S. Toral, M.R. Arahal, M.J. Duran, R. Gregor, "A proof of concept study of predictive current control for VSI driven asymmetrical dual three-phase AC machines," accepted for publication in the IEEE Trans. on Industrial Electronics, 2008.

[12] M.R. Arahal, F. Barrero, S. Toral, M.J. Duran, R. Gregor, "Multiphase current control using predictive models," accepted for publication in Control Engineering Practice, 2008.

[13] Duran, M., Toral, S., Barrero, F., Levi, E., "Real-time implementation of multidimensional five-phase space vector pulse width modulation", Electronics Letters 43 (17), 949-950, 2007.

[14] R. Kennel, A. Linder, "Predictive control of inverter supplied electrical drives," PESC 00, vol. 2, pp. 761-766, 2000.

[15] A. Linder, R. Kennel, "Model Predictive Control for Electrical Drives," PESC 05, pp. 1793-1799, 2005.

[16] J. Rodriguez, J. Pontt, C.A. Silva, P. Correa, P. Lezana, P. Cortes, U. Ammann, "Predictive Current Control of a Voltage Source Inverter", IEEE Trans. on Ind. Electr., 54(1), pp. 495 - 503, 2007.

[17] R. Vargas, P. Cortes, U. Ammann, J. Rodriguez, J. Pontt, "Predictive Control of a Three-Phase Neutral-Point-Clamped Inverter”, IEEE Trans. on Ind. Electr., 54(5), pp.2697-2705, 2007.

[18] R. Vargas, U. Ammann, J. Rodriguez and J. Pontt, "Reduction of Switching Losses and Increase in Efficiency of Power Converters using Predictive Control”, PESC 2008, pp.1062 -1068, 2008.

[19] F. Morel, X. Lin-Shi, J.M. Rétif, B. Allard, "A predictive current control applied to a permanent magnet synchronous machine, comparison with a classical direct torque control," Electric Power Systems research, vol. 72, pp. 1437-1447, 2008.

[20] F. Morel, J.M. Rétif, X. Lin-Shi, C. Valentin, "Permanent Magnet Synchronous Machine Hybrid Torque Control," IEEE Transactions on Industrial Electronics, vol. 55, no. 2, pp. 501-511, 2008. 